\title{
REPORTS AND DISCUSSION.
}

\section{THE NEW PSYCHOLOGY BUILDING AT THE UNIVER- SITY OF CHICAGO.}

With the beginning of the present academic year the department of psychology in the University of Chicago takes up its abode in new and commodious quarters, a brief account of which may be of interest to readers of this journal.

The department has been given for its exclusive occupancy a three story and basement stone-and-brick building with a ground plan of sixty by forty feet. This affords upwards of nine thousand square feet of available floor space.

The north half of the basement ( $60 \times 20$ feet) is devoted to a draughting room and shop. The shop will be on a distinctly larger scale than heretofore and after the present year will undertake, under the joint direction of Professor C. H. Judd and the writer, to manufacture psychological apparatus for other laboratories as well as materials for our own use. The south half of the basement is fitted up as a dark-room. Among other devices this room is supplied with a heliostat and an arc light. Either sunlight or artificial light is thus available for color work.

On the ground floor are two large lecture rooms supplied with dark curtains and projection lanterns. The lecture desks, ten feet in length, are fitted with electricity for light and power, with gas and air pressure, while water is immediately at hand. The remainder of the space on this floor is given over in part to rooms reserved for work in the training courses, e. g., a suite for acoustical work, a room for the study of cutaneous sensations, and so forth. The rooms not thus accounted for are used for the storage, repair and care of apparatus.

On the second floor is the department library and a large seminar room for the exclusive use of advanced graduate students. Here each may have his own desk room, lock-drawers for papers, etc. On this floor also are the department offices and a number of additional rooms for work in the training courses; for example, a specially prepared room for work on smell and taste, and a suite for experiments in vision.

The top floor is entirely reserved for research purposes. Fourteen rooms are available, the average size being about twelve feet square. Half of these have sunlight all day, while three have only north light and the other four get the sun at the ends of the day. A small photo- 
graphic dark-room supplements the large plant in the basement. All of these rooms are high above the noise and dirt of the street. A dumb-waiter at the rear of the building permits the easy carrying of heavy apparatus up and down from one floor to another.

The electrical arrangements differ somewhat from those installed in other psychological laboratories and promise great convenience and efficiency. Every room has electric lights and plugs from which a direct current can be drawn. Gas is also available in a number of places, although it is not intended for illuminating purposes. Arc lights are supplied to the basement dark-room and to the lecture room lanterns. Electric power adequate for running the lathes and other machines is supplied to the shop. A storage battery of twelve large units is by appropriate connections made available for use anywhere in the building, delivering any amount of current desired up to the limit of its capacity. A circuit for high amperage motors supplies all the rooms where such apparatus may be required. The fourteen research rooms are joined to one another by six circuits so arranged that by a system of plugging one or more circuits may be made to unite any room in the series with anyother. Any room may also be connected with the floors below. The system thus permits the maximum of flexibility in conducting experiments where observer and experimenter require to occupy separate and isolated rooms.

A series of speaking tubes unites distant parts of the building with one another, e.g., the shop with the research rooms and with the director's office. Hot and cold water are supplied on every floor, as well as wash-rooms and sinks for cleansing apparatus. Air pressure is also available at a number of points.

The building formerly used as a laboratory, together with the adjacent yard, will be employed hereafter solely for the work in animal psychology. This will obviate the difficulties, hitherto so serious, of keeping animals in a building used for general academic purposes.

With two entire buildings at its disposal the work of the department can be carried on with a degree of convenience and efficiency previously impossible.

UnIVERSITY OF CHICAGo.

James R. Angell.

\section{'MAGNETIC SENSE' OF DIRECTION.}

So far as $I$ know there has been no scientific investigation of the possible presence of a sense of north-south direction in man. There are some allusions to such a sense in fiction (see du Maurier's Martian) and it appears to be a somewhat popular belief. 